REVIEW

\title{
Long term motor complications of levodopa: clinical features, mechanisms, and management strategies
}

\author{
B R Thanvi, T C N Lo
}

Postgrad Med J 2004;80:452-458. doi: 10.1136/pgmj.2003.013912

Levodopa is the most effective symptomatic treatment of Parkinson's disease. However, after an initial period of dramatic benefit, several limitations become apparent including, "dopa resistant" motor symptoms (postural abnormalities, freezing episodes, speech impairment), "dopa resistant" non-motor signs (autonomic dysfunction, mood and cognitive impairment, etc), and/or drug related side effects (especially psychosis, motor fluctuations, and dyskinesias). Motor complications include fluctuations, dyskinesias, and dystonias. They can be very disabling and difficult to treat. Therefore, strategies should ideally be developed to prevent them. Though mechanisms underlying motor complications are only partially understood, recent work has revealed the importance of pulsatile stimulation of postsynaptic dopamine receptors and the disease severity. As a result of intermittent stimulation there occurs a cascade of changes in cell signalling leading to upregulation of the N-methyl-Daspartate subtype of gamma-aminobutryric acid-ergic neurones. Modified preparations of levodopa (controlled release preparations, liquid levodopa), catecholamine-omethyltransferase inhibitors, dopamine agonists, amantidine, and various neurosurgical approaches have been used in the prevention and/or treatment of motor complications. Current management of motor complications is less than satisfactory. With better understanding of the pathogenetic mechanisms, it is hoped that future therapeutic strategies will provide a safer and targeted treatment.

See end of article for authors' affiliations

Correspondence to: Dr B R Thanvi, Department of Integrated Medicine, Leicester Royal Infirmary, University Hospitals of Leicester NHS Trust Infirmary Squire, Leicester LE1 5WW, UK; bthanvi@ hotmail.com

Submitted 22 August 2003 Accepted

11 February 2004 n 1967, Cotzias and colleagues demonstrated the dramatic improvement in motor symptoms of Parkinson's disease using large doses of levodopa. ${ }^{1}$ The foundation of this study was made by the earlier works of Carlssone et al who demonstrated reversal of akinesia in reserpinised animals after levodopa administration, suggesting a role of dopamine deficiency in Parkinson's disease, ${ }^{2}$ and of Ehringer and Hornykiewicz who reported deficiency of dopamine in the striatum. ${ }^{3}$ Cotzias's work was a landmark study that led to widespread use of levodopa in Parkinson's disease. Parkinson's disease was the first neurodegenerative disease for which evidence for an underlying biochemical deficit (of dopamine) was beginning to be available.
Therefore, treatment of Parkinson's disease with levodopa (a dopamine precursor) had a strong theoretical basis.

The therapeutic benefit of levodopa, however, was restricted by the significant nausea and vomiting associated with it due to its peripheral metabolism. Discovery of peripheral dopa decarboxylase inhibitors in the mid-1970s greatly reduced these gastrointestinal side effects of levodopa and currently it is practically always used with a peripheral dopa decarboxylase inhibitor.

More than 35 years after its introduction, levodopa still remains the most effective treatment for Parkinson's disease and is considered as the "gold standard" therapy. ${ }^{4}$ In fact, the diagnosis of Parkinson's disease becomes questionable if a patient fails to respond to an adequate dose of levodopa. ${ }^{5}$ However, within a few years of introduction of levodopa, clinicians recognised several problems associated with its continued use. ${ }^{6}$ In the early stages of the disease the response to levodopa is sustained, despite its relatively short half life ( $\sim 1.5$ hours $)$. This is presumably due to the preserved capacity of the presynaptic nerve terminals to store dopamine. Patients do not notice any deterioration in their symptoms of Parkinson's disease even if they miss out a few doses. As the disease progresses, with continued loss of substantia nigra, the beneficial effect of each dose of levodopa progressively gets shorter. Patients notice deterioration in their symptoms an hour or two before their next due dose, the so-called "end of dose deterioration" or "wearing off". With further progression of the disease, more unpredictable complications, such as motor fluctuations, "on/ off" phenomena, and dyskinesias appear.

Motor complications associated with long term levodopa treatment in Parkinson's disease are common and they can be more disabling than the disease itself. Recently, there has been a great interest in the study of mechanisms underlying the emergence of motor complications associated with the chronic use of levodopa and possible therapeutic strategies to prevent or treat these complications. Pulsatile stimulation of postsynaptic receptors by levodopa (with a short half life) coupled with the progressive loss of nigrostrital neurones are considered to be the most important factors in the causation of these

\footnotetext{
Abbreviations: $A A D C$, aromatic amino acid decarboxylase; COMT, catecholamine-omethyltransferase; GABA, gamma-aminobutryric acid MPTP, 1-methyl-4-phenyl-1,2,3,6-tetrahydropyridine; NMDA, N-methyl-D-aspartate
} 
complications. Dopamine agonists have a longer half life and are being increasingly used in the treatment of Parkinson's disease, either as monotherapy or in conjunction with levodopa. Several studies have shown significantly fewer motor complications with dopamine agonists as an initial therapy of Parkinson's disease compared with treatment with levodopa. However, dopamine agonists may not be well tolerated by frail elderly patients and those with cognitive impairment. They are also associated with excessive daytime sleepiness. With progression of Parkinson's disease, there is often a need to add levodopa when dopamine agonists alone fails to improve symptoms. Inhibitors of catecholamine-omethyltransferase (COMT) are useful to treat simple end of dose fluctuations, but may worsen dyskinesias. Therefore, the problem of motor complications with long term levodopa therapy remains a real challenge in the management of the disease. It is important to know basic synaptic neurophysiology and the clinical pharmacology of levodopa in order to understand the mechanisms underlying the production of motor complications.

\section{BASIC NEUROPHYSIOLOGY}

\section{Endogenous dopamine synthesis}

Amino acid tyrosine is a precursor of dopamine (and other catecholamines like epinephrine and norepinephrine). It converts into dopamine by the actions of two enzymes (fig 1). All catecholamine neurones contain an enzyme called tyrosine hydroxylase. Tyrosine hydroxylase converts tyrosine to L-dihydroxyphenylalanine (levodopa). Dopa is converted into dopamine by the enzyme dopa decarboxylase, also called aromatic amino acid decarboxylase (AADC).

\section{Metabolism and clinical pharmacology of exogenous levodopa}

When administered orally, levodopa is absorbed mainly in the duodenum and the proximal bowel. Peak serum levels are reached at 30 to 60 minutes. Absorption of levodopa is reduced by large neutral amino acids and by the delayed gastric emptying. Exogenously administered levodopa is extensively metabolised peripherally to dopamine by AADC and to 3-o-methyldopa by the enzyme COMT (fig 2).

Unlike dopamine, levodopa crosses the blood-brain barrier and is taken up by the nigral dopaminergic neurones. In the nigral neurones it is converted to dopamine by AADC (fig 3). Dopamine is stored into vesicles of the presynaptic neurone from which it is released into the synaptic cleft. Dopamine acts as a neurotransmitter by acting on the postsynaptic dopamine receptors. Metabolism of dopamine involves its reuptake by the presynaptic neurone and the enzymatic conversion to 3, 4, dihydroxyphenyl acetic acid by mono-

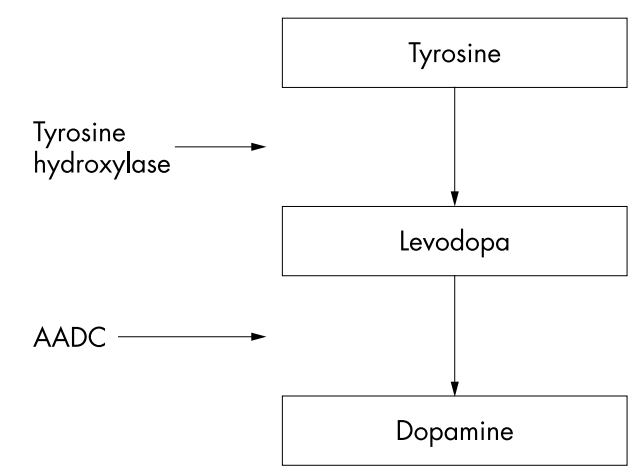

Figure 1 Steps in endogenous dopamine synthesis (AADC, aromatic amino acid decarboxylase).

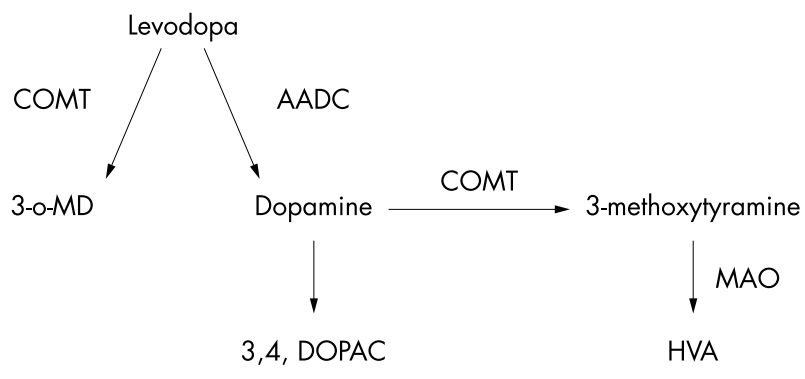

Figure 2 Scheme of levodopa metabolism (COMT, catecholamine-omethyl transferase; AADC, aromatic amino acid decarboxylase; 3-oMD, 3-o-methyldopa; MAO, monoamine oxidase; HVA, homovinillic acid; DOPAC, dihydroxyphenyl acetic acid).

amine oxidase inhibitor and to 3-methoxytyramine by COMT.

Levodopa is always given with a peripheral decarboxylase inhibitor (carbidopa or benserazide) to reduce its conversion to dopamine at the periphery. This allows low doses of levodopa and reduces the incidence of side effects like nausea and vomiting. The bioavailability of levodopa can be increased by the inhibition of COMT enzyme. Entacapone inhibits COMT at the periphery and tolcapone does it both centrally and peripherally. Selegiline is a monoamine oxidase$\mathrm{B}$ inhibitor that increases the dopamine levels. Dopamine agonists act on postsynaptic receptors.

Levodopa has a short half life of $\sim 90$ minutes. However, in the early stage of Parkinson's disease, clinical effects of levodopa last for several hours and patients often derive great benefit with levodopa administered only twice a day (fig 4A). Even if a patient misses an occasional dose of levodopa, no significant return/deterioration of symptoms occurs. There are no dyskinesias. The plasma levels of levodopa remain smooth throughout the 24 hour period. This is explained on the basis of preserved capacity of the presynaptic neurones to store levodopa for its subsequent slow release. As the disease advances, there is a progressive loss of neurones. Consequently, the duration of clinical benefit derived from each levodopa dose progressively shortens and patients often notice return of their symptoms long before the next due

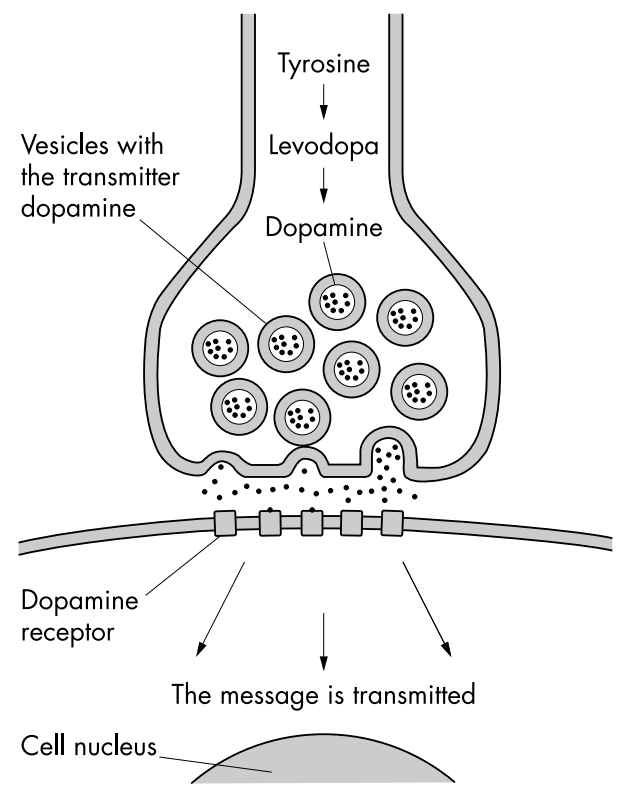

Figure 3 Nigrostriatal dopaminergic synapse. 
dose, the so-called "end of dose deterioration" or the "wearing off" (fig 4B). This can initially be improved by increasing the frequency of levodopa doses. With further progression of the disease, however, the wearing off periods become more frequent and they do not necessarily respond to the increased frequency of levodopa doses. The response to levodopa becomes unpredictable and the patient may frequently switch from a mobile state to complete immobility, the so-called "on/off" states (fig 4C). The plasma levels of levodopa show extreme variations and often are outside the therapeutic range, producing akinesia at subtherapeutic level and excessive movements (dyskinesias) at peak levels. With further progression of the disease, dyskinesias become more complex in pattern (for example, they may also appear when plasma levodopa levels are low) and patients may also notice periods when there is practically no response ("no on" state) to an administered dose of levodopa. It is believed that plasma levels of levodopa have an inductive role in production of motor complications but are not the sole explanation for their pathogenesis.

\section{Pathogenetic mechanism(s) of long term motor complications}

The pathogenesis of motor complications associated with chronic levodopa therapy is only partially understood. There has been extensive research in recent years that has shed some light into this matter. It is generally agreed that two factors are important in the aetiopathogenesis of motor complications: (1) disease severity and (2) levodopa use.

The degree of nigrostriatal damage (disease severity) has been shown in several studies to be a very important risk factor for the development of motor complications. ${ }^{7-9}$ This is also supported by observations that dyskinesias usually do not develop when levodopa is used in the treatment of conditions that are not associated with nigrostriatal damage-for example, levodopa responsive dystonia, ${ }^{10}$ secondary parkinsonism, and amyotrohic lateral sclerosis. ${ }^{11}{ }^{12}$ In monkeys exposed to 1-methyl-4-phenyl-1,2,3,6-tetrahydropyridine (MPTP), dyskinesias are most easily evoked in animals with greater than $95 \%$ dopamine depletion. ${ }^{13}$ As a corollary to this, it is shown that in asymmetric Parkinson's disease, dyskinesias tend to appear first on the worst affected side.'

Chronic dopaminergic therapy is the other (and probably the most) important factor that is required for the production of dyskinesia. It is shown that untreated patients do not develop dyskinesia even if their disease is advanced and that a prolonged period of levodopa treatment is needed to produce dyskinesia in MPTP-exposed primates. ${ }^{14}{ }^{15}$

Concept of continuous versus pulsatile dopaminergic stimulation: extensive research has been done in recent years in an attempt to explain how these two factors (disease severity and chronic dopaminergic treatment) interact in producing the motor complications. It should be noted that under physiological conditions, presynaptic dopaminergic neurones in nigrostriatal pathways fire tonically, releasing dopamine in a continuous manner. This in turn causes steady stimulation of the postsynaptic receptors. It was initially thought that loss of presynaptic dopaminergic neurones as a result of advancing disease (leading to reduced synthesis, storage, and release of dopamine) solely accounted for the genesis of fluctuations and dyskinesias. ${ }^{16}$ However, recent work has challenged this notion and it now seems that changes in postsynaptic receptors are probably more important. It is believed that the use of exogenous levodopa (with its short half life) causes intermittent release of dopamine from the presynaptic neurones, and hence, non-physiological, pulsatile (intermittent) stimulation of the postsynaptic receptors. The pulsatile stimulation presumably produces changes in the postsynaptic receptors that are instrumental in the pathogenesis of motor
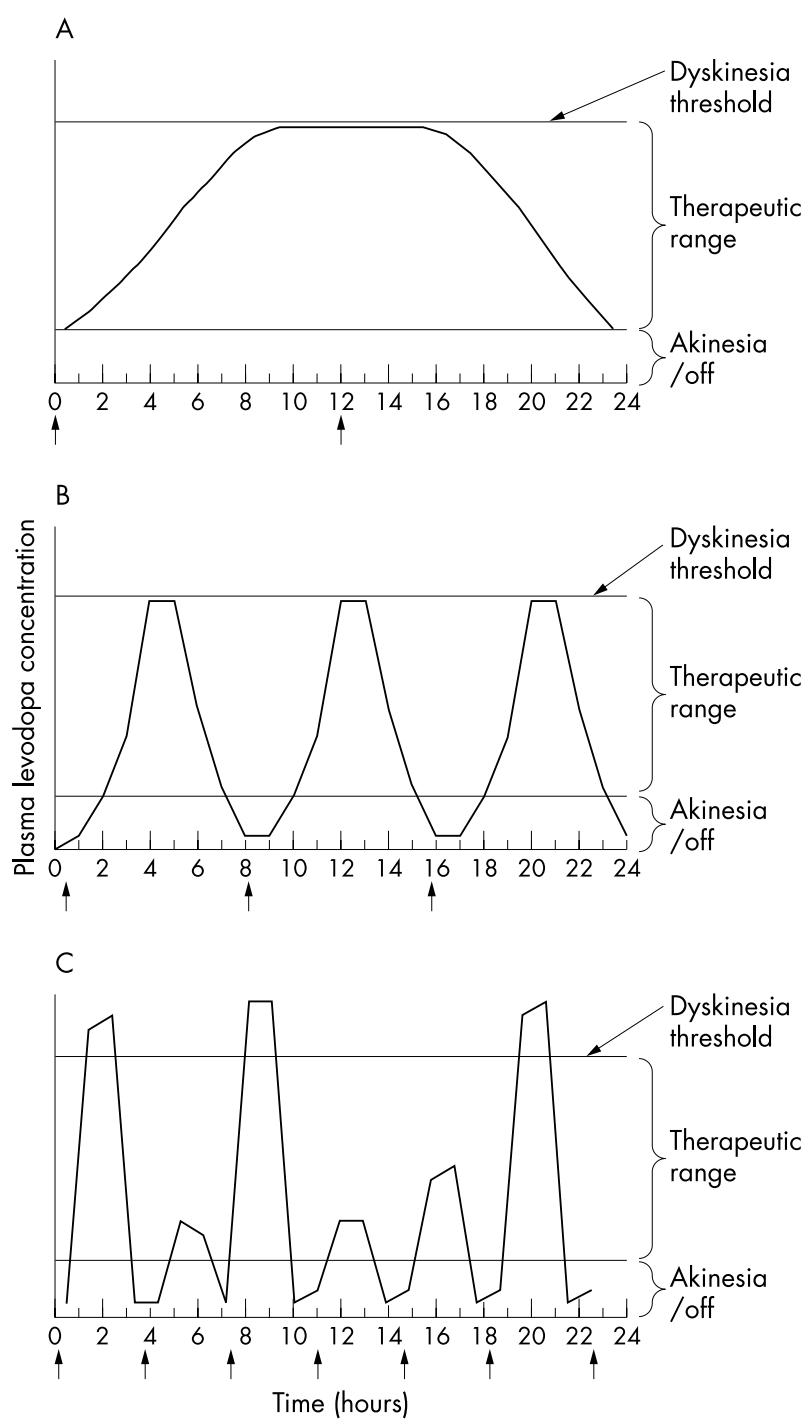

Figure 4 (A) Schematic graph to show the relationship between plasma levodopa levels and the clinical effects in early Parkinson's disease. (B) Schematic graph showing dose responsive fluctuations in advancing Parkinson's disease. (C) Schematic graph to show unpredictable fluctuations and dyskinesias unrelated to dose administrations ("yoyoing") in advanced Parkinson's disease. Arrows indicate time of levodopa administration.

complications. Several lines of evidence favour this theory. Motor complications can be delayed and even ameliorated by the use of continuous intraduodenal ${ }^{17}$ or intravenous infusions ${ }^{18}$ of levodopa, continuous transdermal delivery of apomorphine $^{19}$ or by use of dopamine agonists. ${ }^{20-24}$ The following sequence of events has been proposed to explain the mechanisms of long term motor syndrome. ${ }^{25-28}$

The "wearing off" fluctuations, typically the first motor complication to become clinically evident, initially result from loss of buffering normally provided by presynaptic striatal dopaminergic neurones. With disease progression and continuing levodopa treatment, the postsynaptic receptors are stimulated in an intermittent ("pulsatile") manner. Both dopamine and $N$-methyl-D-aspartate (NMDA) receptors are expressed along the dendritic spines of striatal medium sized gamma-aminobutyric acid (GABA)-ergic neurones. Corticostriatal glutamatergic projections synapse primarily at the distal tips of these spines, whereas nigrostriatal dopaminergic fibres synapse slightly more proximally, allowing close 
functional alterations. Chronic intermittent stimulation of normally tonically active dopaminergic receptors brings about alterations in cell signals in striatal dopaminergic medium spiny neurones. This causes potentiation of the GABA-ergic efferents, particularly, glutamate receptors of the NMDA subtype. Glutamate-mediated striatal sensitisation subsequently modifies basal ganglia output in ways that favour the appearance of motor complications. ${ }^{26}{ }^{27}$ In postmortem samples from levodopa treated parkinsonian patients, increased GABA (A) receptors content in the internal globus pallidus were found in dyskinetic parkinsonian patients compared with non-dyskinetic patients. ${ }^{28}$ Further support for this theory comes from animal studies showing reduction of dyskinesias using NMDA antagonist dextrophan with levodopa in MPTP treated monkeys. ${ }^{29}$

The pathogenesis of long term motor complications of levodopa is summarised in fig 5.

\section{CLINICAL ASPECTS}

After five years of levodopa therapy, nearly $50 \%$ of patients develop motor complications and after 10 years nearly $100 \%$ of patients are affected by them. ${ }^{30}$ These complications tend to be more common in patients with young onset Parkinson's disease. Several studies have shown that motor complications are significantly more common with levodopa therapy compared with monotherapy with dopamine agonists..$^{20-22} 31$ Therefore, a link between chronic levodopa use and emergence of motor complications is suggested. Unfortunately, once established, these complications can be resistant to medical therapy. The motor complications can be considered as hypokinetic and hyperkinetic phenomena (box 1).

(1) Hypokinetic phenomena (response fluctuations) In early stage of Parkinson's disease, patients derive great benefit with levodopa taken two to three times a day. The drug is most effective against akinesia and rigidity. Although levodopa has a short half life ( $t \frac{1}{2} \quad 1.5$ hours), the clinical benefit lasts for several hours in the early stage of the disease. This has been attributed to suprasensitivity from chronic denervation and the preserved capacity of presynaptic nerve terminals to store dopamine in the initial stages. With disease progression, the useful antiparkinsonian effect of each levodopa dose lasts a progressively shorter time. Patients have to use levodopa more frequently for relief from parkinsonian symptoms. They find that the dose that used to give them relief from their motor symptoms for several hours is now effective for progressively shorter

Nigrostriatal damage
Reduced synthesis, storage,
and release of dopamine
Loss of buffering capacity
Early wearing off
fluctuations

Figure 5 Flow chart showing possible mechanisms in production of motor complications due to chronic levodopa treatment.
Box 1: Long term motor complications of

levodopa treatment

Response fluctuations (hypokinetic phenomena):

- End of dose deterioration ("wearing off').

- Unpredictable "on/off" (yo-yoing).

- Early morning hypokinesia or akinesia.

- Short duration "off" period freezing.

- Short duration "on" period freezing.

Involuntary movements (hyperkinetic phenomena):

- Peak dose dyskinesia.

- Diphasic dyskinesia.

- Off period dystonia.

- Early morning dystonia.

- Biphasic dystonia.

periods ("wearing off" phenomenon"). Initially, these "wearing off" periods occur in predictable fashion- "end of dose deterioration". With further disease progression, the response to levodopa becomes unpredictable and patients may fluctuate between mobile ("on") state and immobility ("off") state in a matter of minutes ("like flicking on a light switch"). "Off" periods may manifest as freezing, falls, stiffness, and sometimes as panic attacks. Early morning hypokinesia or akinesia, short duration "off" period freezing, and short duration "on" period freezing are also noted with the disease progression, though their relationship to chronic levodopa therapy is not well established. "Off" period freezing can be improved by increasing levodopa dose frequency or by controlled released levodopa preparations. However, "on" period freezing is very difficult to treat.

\section{(2) Hyperkinetic phenomena (dyskinesias and dystonias)}

In addition to the fluctuations, long term levodopa use is also complicated by appearance of abnormal involuntary movements, called dyskinesias and dystonias. Dyskinesias may be choreiform (brief, jerky movements, usually affecting limbs) or athetoid (twisting movements affecting limbs, face, or trunk). Initially, dyskinesias arise as a result of high levodopa dosage and can be reduced or ameliorated by the dose reduction. However, as the disease advances, they can occur regularly at the time of peak plasma levels of levodopa (peak dose dyskinesia). Uncommonly, dyskinesia can occur at peak levels as well as when the effect of an individual dose is waning, giving rise to the sequence of dyskinesiaimprovement-dyskinesia, also called diphasic dyskinesias. Dyskinesias can be exhausting for the patient and frightening to the unaware carer. When dyskinesias occur as part of a peak dose effect, patients may be mobile at the time of dyskinesia and akinetic when not dyskinetic. This has important implications in the treatment of dyskinesia as patients may prefer dyskinesia with mobility to no dyskinesia and immobility. The other involuntary movements are dystonias (painful muscle contractions causing unusual postures). Early morning painful foot dystonia (painful curling movements of foot) is a common form of dystonia. Dystonias are not clearly linked with chronic levodopa treatment, and interestingly, early morning dystonias often respond favourably to an additional levodopa dose or a controlled release preparation of levodopa taken on a previous night. 


\section{MANAGEMENT OF LONG TERM MOTOR COMPLICATIONS OF LEVODOPA}

Levodopa is the most effective symptomatic treatment for Parkinson's disease. Despite the introduction of dopamine agonists and COMT inhibitors in the market, levodopa consumption was shown to be on the rise in a Swedish study. ${ }^{32}$ Most experts use levodopa treatment as the initial choice in frail elderly patients. Even when patients are initially treated with dopamine agonists, they often need additional levodopa after a few years of therapy for their symptom control. Therefore, treatment (and preferably prevention) of motor complications would certainly be the most desired aim while using levodopa on a long term basis. Simple measures-such as taking levodopa before meals, avoiding a high protein diet, etc-should be considered before altering the levodopa dose or employing additional therapy in patients with end of dose deterioration. Based on the current knowledge of mechanisms underlying pathogenesis of motor complications of chronic levodopa treatment, the following therapeutic strategies have been advocated (table 1).

Table 1 Possible therapeutic options in the management of long term motor complications of levodopa therapy

\begin{tabular}{|c|c|}
\hline Therapeutic strategy & Comments \\
\hline $\begin{array}{l}\text { Taking levodopa before } \\
\text { meals }\end{array}$ & $\begin{array}{l}\text { Should be tried in the initial stages before } \\
\text { adding other drug; helps to achieve better } \\
\text { absorption of levodopa. Limited use in late } \\
\text { stages }\end{array}$ \\
\hline Low protein diet & $\begin{array}{l}\text { Absorption of levodopa is reduced by amino } \\
\text { acids in the diet. Diet low in protein may help } \\
\text { in early fluctuations }\end{array}$ \\
\hline $\begin{array}{l}\text { COMT inhibitors } \\
\text { (entacapone, tolcapone) }\end{array}$ & $\begin{array}{l}\text { Attractive theoretical basis, shown to be } \\
\text { effective in randomised trials. Useful in motor } \\
\text { fluctuations by increasing duration of on time. } \\
\text { Possible worsening of dyskinesia reported. } \\
\text { Tolcapone has potentially life threatening } \\
\text { hepatotoxicity }\end{array}$ \\
\hline Dopamine agonists & $\begin{array}{l}\text { Shown in several studies to be effective in } \\
\text { prevention and treatment of motor } \\
\text { complications. Probably should be the initial } \\
\text { drug of choice in young and biologically fit } \\
\text { older patients. Possible neuroprotection. } \\
\text { Common short term side effects lead to } \\
\text { frequent dropouts }\end{array}$ \\
\hline $\begin{array}{l}\text { Amantidine and other } \\
\text { NMDA antagonists }\end{array}$ & $\begin{array}{l}\text { In some trials, shown to be useful against } \\
\text { motor complications; consistent with theory of } \\
\text { upregulation of NMDA receptors. Evidence } \\
\text { insufficient }\end{array}$ \\
\hline $\begin{array}{l}\text { Controlled release } \\
\text { preparations of } \\
\text { levodopa }\end{array}$ & $\begin{array}{l}\text { May be effective in simple end of dose } \\
\text { deterioration. Not effective in severe } \\
\text { fluctuations and dyskinesia }\end{array}$ \\
\hline $\begin{array}{l}\text { Continuous } \\
\text { intraduodenal/ } \\
\text { intravenous levodopa } \\
\text { infusion }\end{array}$ & $\begin{array}{l}\text { Shown to be effective in preventing and } \\
\text { treating motor complications. Practicalities } \\
\text { limit routine use }\end{array}$ \\
\hline $\begin{array}{l}\text { Liquid levodopa } \\
\text { preparations, in } \\
\text { frequent dosage }\end{array}$ & $\begin{array}{l}\text { Fast and predictable response, effective } \\
\text { against motor complications. Small sized } \\
\text { trials, cumbersome method }\end{array}$ \\
\hline $\begin{array}{l}\text { Neurosurgical } \\
\text { approaches } \\
\text { (thalamotomy, } \\
\text { pallidotomy, deep } \\
\text { brain stimulation) }\end{array}$ & $\begin{array}{l}\text { Small studies have shown benefit. Limitations } \\
\text { of patient selection, postoperative } \\
\text { complications and invasiveness }\end{array}$ \\
\hline
\end{tabular}

\section{(1) COMT inhibitors}

Entacapone and tolcapone are examples of commercially available products that inhibit the enzyme, COMT. This is one of the enzymes normally involved in the breakdown of levodopa. Entacapone inhibits this enzyme peripherally and tolcapone inhibits it centrally as well as peripherally. These drugs prolong the antiparkinson effect of the levodopa and also allow reduction of the dose. As continuous dopaminergic stimulation is considered to be important in reducing the incidence of motor complications associated with long term levodopa therapy, the combination of COMT inhibitors and levodopa appears to be an attractive theoretical proposition. Recent short term studies have shown that the addition of entacapone to levodopa improves its efficacy in patients with fluctuations and reduces wearing off and end of dose akinesia. ${ }^{33-35}$ Some authorities have suggested a combination of levodopa and COMT inhibitors to be used from the outset in the management of Parkinson's disease. ${ }^{36}$ However, long term studies using COMT inhibitors with levodopa are awaited. Though more effective than entacapone, tolcapone is associated with a potentially fatal hepatotoxicity and therefore has been withdrawn from the European market. However, it is still available in the USA and can be used in patients who fail to respond to entacapone and who agree to sign a consent form acknowledging the possible side effect of hepatotoxicity. Recently, a combination of levodopa/carbidopa and entacapone has been introduced in the USA. This appears to be an attractive theoretical approach of enzyme blockade to enhance levodopa bioavailability.

\section{(2) Dopamine agonists}

Dopamine agonists have been shown in various studies to delay the onset of motor complications when used as monotherapy and/or to diminish them when used in dyskinetic patients. ${ }^{20-24}$ Dopamine agonists have a longer half life than levodopa and act directly on the dopamine receptors. In a five year study in early Parkinson's disease, ropinirole was found to be effective with a reduced risk of dyskinesia when used alone or with supplemental levodopa. ${ }^{20}$ Cabergoline, ${ }^{22}$ apomorphine, ${ }^{19}$ and lisuride ${ }^{24}$ have all been shown to have reduced incidence of motor complications than levodopa treatment. This has led many clinicians to use dopamine agonists as an initial treatment of choice in Parkinson's disease, especially in younger patients. Transdermal apomorphine treatment has been shown to improve dyskinesias when used for motor fluctuations in Parkinson's disease. However, dopamine agonists may be poorly tolerated, especially by frail older patients and they may be less potent antiparkinsonian drugs than levodopa. In several studies using dopamine agonists as the initial treatment, significant number of patients discontinued dopamine agonists and supplemental levodopa was required in a number of patients to control Parkinson's disease. Excessive daytime sleepiness has also been reported with dopamine agonists. In some cases, this may lead to occurrence of sudden "sleep attacks" and road traffic accidents.

\section{(3) Amantidine and NMDA antagonists}

As discussed under pathogenetic mechanisms, there is an upregulation of NMDA receptor subtype of GABA-ergic efferents caused by the pulsatile stimulation of dopaminergic neurones in patients with motor complications. It is reported that amantadine, an NMDA receptor antagonist, may reduce dyskinesias in patients with Parkinson's disease without worsening parkinsonian symptoms. ${ }^{37} 38$ However, a recent Cochrane analysis of trials using amantidine in treating motor complications has commented that the evidence for its efficacy is insufficient. ${ }^{39}$ Dextromethorphan, another NMDA antagonist has been shown to reduce motor complications when given with levodopa. ${ }^{29}$ 
(4) Long acting levodopa preparations and continuous levodopa delivery

Levodopa is the most effective antiparkinsonian drug available to us. Therefore, it is highly desirable to modify standard levodopa preparations in a way that would avoid the motor complications. The short half life of levodopa is considered to be responsible for the motor complications. Pulsatile stimulation of postsynaptic neurones has been suggested as an important factor in production of motor complications. It is tempting to think that long acting preparations of levodopa will provide a smooth plasma concentration and, therefore, will minimise the risk of complications. However, apart from some possible benefit in early end of dose fluctuations and early morning akinesia, the controlled release preparations have shown no advantage over standard levodopa formulations in reducing motor complications ${ }^{40-42}$ They may worsen peak dose dyskinesia. Liquid preparations of levodopa have been shown to have a faster onset of action and when used in a frequent dose schedule (for example, one hourly), may reduce motor fluctuations. ${ }^{43}$

Giving levodopa by intraduodenal ${ }^{17}$ or intravenous infu$\operatorname{sion}^{18}$ has been shown to reduce motor complications. However, practical problems associated with these methods are obvious limiting factors. Other possible methods of continuous levodopa delivery include transdermal and intrastriatum approaches. Using small and frequent doses of oral standard levodopa unfortunately leads to higher rates of drug failure.

\section{(5) Miscellaneous drugs}

There have been claims of effectiveness of various drugs including clozapine (an atypical neuroleptic), fluoxetine (an antidepressant), propranolol (a $\beta$-blocker), etc. However, these are based mainly on trials in small number of patients. The search for an ideal agent to treat motor complications of levodopa therapy continues.

\section{(6) Neurosurgery}

Medical treatment of motor complications remains unsatisfactory. Neurosurgery has helped in selected cases to treat these complications. In a recent study, bilateral deep brain stimulation of the subthalamic nuclei has been shown to be effective in treating dyskinesia and fluctuations. ${ }^{44}$ In another study, bilateral stimulation of the subthalamic nucleus or pars interna of the globus pallidus was associated with significant improvement in motor function in patients with Parkinson's disease whose condition could not be further improved with medical therapy ${ }^{45}$ Thalamotomy ${ }^{46}$ and posteroventral pallidotom $y^{47}$ have also been found to be effective in treating motor complications.

\section{FUTURE PROSPECTS}

Currently, pathogenetic mechanisms underlying motor complications of levodopa are better understood. Future research would hopefully provide a clearer picture of actual signalling processes involved at the molecular level. Drugs that target signalling proteins within striatal spiny neurones or those that interact extracellularly with non-dopaminergic receptors such as AMPA and NMDA, adenosine, adrenergic, opioid, and serotonergic, may prove safer and more effective. ${ }^{26}$ The cannabinoid receptor agonists ${ }^{48}$ and adenosine receptor antagonists ${ }^{49}$ have been found in animal studies to be useful in the treatment of motor complications in Parkinson's disease. The role of serotoninergic mechanisms in motor dysfunction in Parkinson's disease has been suggested based on usefulness of drugs able to block serotonin 5HT2A/C receptors in patients with certain extrapyramidal movement disorders. As a corollary, quetiapine (an atypical neuroleptic) has been shown to be effective against motor complications. ${ }^{50}$
Future therapy might include targeted delivery of trophic factors or genes involved in the pathogenesis of the disease. ${ }^{51}$ Novel experimental restorative surgical therapies aim to replace or regenerate degenerating dopaminergic neurones..$^{52}$ These include embryonic mesencephalic tissue transplantation, human embryonic stem cell transplantation, and gene derived methods of intracerebral implantation of growth factors and dopamine-producing cell lines.

\section{Authors' affiliations}

B R Thanvi, Department of Integrated Medicine, Leicester Royal Infirmary, University Hospitals of Leicester NHS Trust, Leicester, UK T C N Lo, Leicester General Hospital, University Hospitals of Leicester NHS Trust, Leicester, UK

\section{REFERENCES}

1 Cotzias GC, Van WM, Schiffer LM. Aromatic amino acids and modification of parkinsonism. N Engl J Med 1967;276:374-9.

2 Carlssone A, Lindquist M, Magnusson T. 3, 4-Dihydroxy-phenylalanine and 5-hydroxytryptaphan as reverie antagonists. Nature 1957;180:1200-1.

3 Ehringer $\mathrm{H}$, Hornykiewicz $\mathrm{O}$. Verteilung von Noradrenalin und Dopamin (3Hydroxy-tyramin) im Gehirn des Menschen und ihr Verhalten bei Erkrankungen des extrapyramidalen Systems. Klin Wochenschr 1960;38:1236-9.

4 Agid Y, Ahlskog E, Albanese A. Members of the Consensus meeting. Levodopa in the treatment of Parkinson's disease: a consensus meeting. Mov Disord 1999; 14:911-13.

5 Quinn N. Parkinson's disease-recognition and differential diagnosis. BMJ 1995;310:447-52.

6 Barbeau A. The clinical physiology of side effects in long term L-dopa therapy. Adv Neurol 1974;5:347-65.

7 Vaamonde J, Ibanez R, Gudin M, et al. Fluctuations and dyskinesias as early L-dopa-induced motor complications in severe parkinsonian patients. Neurologia 2003;18:162-5.

8 Kostic VS, Marinkovic J, Svetel M, et al. The effect of stage of Parkinson's disease at the onset of levodopa therapy on development of motor complications. Eur J Neurol 2002;9:9-14.

9 Horstink MW, Ziilmans JC, Pasman JW, et al. Severity of Parkinson's disease as a risk factor for peak dose dyskinesia. J Neurol Neurosurg Psychiatry 1990;53:224-6.

10 Nyggard TG, Marsden CD, Fahn S. Dopa-responsive dystonia: long treatment response and prognosis. Neurology 1991;41:174-81.

11 Mones RJ, Elizan TS, Siegel GJ. Analysis of L-dopa-induced dyskinesia in 51 patients with parkinsonism. J Neurol Neurosurg Psychiatry 1971;12:668-73.

12 Chase TN, Holden EM, Brody JA. Levodopa induced dyskinesias. Comparison in parkinsonism-dementia and amyotrophic lateral sclerosis. Arch Neurol 1973;29:328-33

13 Schneider JS. Levodopa induced dyskinesia in parkinsonian monkeys: relationship to extent of nigrostriatal damage. Pharmacol Biochem Behav 1989;34:193-6.

14 Boyce S, Rupniak NM, Steventon MJ, et al. Nigrostriatal damage is required for induction of dyskinesia by L-dopa in squirrel monkeys. Clin Neuropharmacol 1990;13:448-58.

15 Clarke CE, Boyce S, Sambrook MA, et al. Timing of levodopa therapy: evidence from MPTP -treated primates. Lancet 1987;i:625.

16 Fabbrini G, Juncos J, Mouradian MM, et al. Levodopa pharmacokinetic mechanisms and motor fluctuations in Parkinson's disease. Ann Neurol 1987;21:370-6.

17 Nyholm D, Askmark H, Gomes-Trolin C, et al. Optimizing levodopa pharmacokinetics: intestinal infusion versus oral sustained-release tablets. Clin Neuropharmacol 2003;26:156-63.

18 Mouradian MM, Heuser IJ, Baronti F, et al. Modification of central dopaminergic mechanisms by continuous levodopa therapy for advanced Parkinson's disease. Ann Neurol 1990;27:18-23.

19 Priano L, Albani G, Calderoni S, et al. Controlled-release transdermal apomorphine treatment for motor fluctuations in Parkinson's disease. Neurol Sci 2002;23(suppl 2):S99-100.

20 Rascol O, Brooks DJ, Korczyn AD, et al. A five-year study of the incidence of dyskinesia in patients with early Parkinson's disease who were treated with ropinirole or levodopa. N Engl J Med 2000;342:1484-91.

21 Maratos EC, Jackson MJ, Pearce RK, et al. Both short- and long-acting D-1/D2 dopamine agonists induce less dyskinesia than L-DOPA in the MPTPlesioned common marmoset (Callithrix jacchus). Exp Neurol 2003;179:90-102.

22 Marco AD, Appiah-Kubi LS, Chaudhuri KR. Use of the dopamine agonist cabergoline in the treatment of movement disorders. Expert Opin Pharmacother 2002;3:1481-7.

23 Cristina S, Zangaglia R, Mancini F, et al. High-dose ropinirole in advanced Parkinson's disease with severe dyskinesias. Clin Neuropharmacol 2003;26: 146-50.

24 Stocchi F, Ruggieri S, Vacca L, et al. Prospective randomized trial of lisuride infusion versus oral levodopa in patients with Parkinson's disease. Brain 2002 Sep; 125(pt 9):2058-66. 
25 Calon F, Di Paolo T. Levodopa response motor complications-GABA receptors and preproenkephalin expression in human brain. Parkinsonism Relat Disord 2002;8:449-54.

26 Oh JD, Chase TN. Glutamate-mediated striatal dysregulation and the pathogenesis of motor response complications in Parkinson's disease. Amino Acids 2002;23(1-3): 133-9.

27 Chase TN. The significance of continuous dopaminergic stimulation in the treatment of Parkinson's disease. Drugs 1998;55(suppl 1):1-9.

28 Calon F, Morissette $M$, Rajput $A H$, et al. Changes of GABA receptors and dopamine turnover in the postmortem brains of parkinsonians with levodopainduced motor complications. Mov Disord 2003;18:241-53.

29 Blanchet PJ, Metman LV, Mouradian MM, et al. Acute pharmacologic blockade of dyskinesias in Parkinson's disease. Mov Disord 1996;11:580-1.

30 Verhagen Metman L. Recognition and treatment of response fluctuations in Parkinson's disease. Amino Acids 2002;23(1-3):141-5.

31 Allain $\mathrm{H}$, Destee $\mathrm{A}$, Petit $\mathrm{H}$, et al. Five-year follow-up of early lisuride and levodopa combination therapy versus levodopa monotherapy in de novo Parkinson's disease. The French Lisuride Study Group. Eur Neurol 2000;44:22-30.

32 Askmark H, Antonov K, Aquilonius SM. The increased utilisation of dopamine agonists and the introduction of COMT inhibitors have not reduced levodopa consumption-a nation-wide perspective in Sweden. Parkinsonism Relat Disord 2003;9:271-6.

33 Brooks DJ, Sagar H, the UK-Irish Entacapone Study Group. Entacapone is beneficial in both fluctuating and non-fluctuating patients with Parkinson's disease: a randomized, placebo-controlled, double blind, six-month study. J Neurol Neurosurg Psychiatry 2003;74:1071-9.

34 Sommer U, Muller A, Herting B, et al. Entacapone for treatment of motor fluctuations in idiopathic Parkinson syndrome. Nervenarzt 2002;73:761-4.

35 Poewe W, Deuschl G, Gordin A, et al. Efficacy and safety of entacapone in Parkinson's disease patients with suboptimal levodopa response: a six-month randomized, placebo-controlled, double blind, study in Germany and Austria (Celomen Study). Acta Neurol Scand 2002;105:1-11.

36 Olanow CW, Obeso JA. Pulsatile stimulation of dopamine receptors and levodopa-induced motor complications in Parkinson's disease: implications for the early use of COMT inhibitors. Neurology 2000;55(11 suppl 4):S72-7, discussion S78-81.

37 Rajput AH, Utti RJ, Lang AE, et al. Amantidine ameliorates levodopa-induced dyskinesia. Neurology 1997;48(suppl 3):A328 (abst).
38 Verhagen Metman L, Del Dotto P, Chase TN. Amantidine palliates motor response complications in Parkinson's disease. Ann Neurol 1997;42:409 (abst).

39 Crosby NJ, Deane KH, Clarke CE. Amantadine for dyskinesia in Parkinson's disease (Cochrane Review). Cochrane Database Syst Rev 2003;(2):CD003467.

40 Cedarbaum JM, Hoey M, McDowell FH. A double blind cross over comparison of Sinemet CR4 and standard Sinemet 25/100 in patients with Parkinson's disease and fluctuating performance. J Neurol Neurosurg Psychiatry 1989:52:207-12.

41 Le Witt PA, Nelson MV, Berchou RC, et al. Controlled release carbidopa/ levodopa (Sinemet 50/200 CR4): clinical and pharmacokinetic studies. Neurology 1989;39(11 suppl):45-53.

42 Block G, Liss C, Reines S, et al. Comparison of immediate-release and controlled-release carbidopa/levodopa in Parkinson's disease. Eur Neurol 1997:37:23-7

43 Kurth MC, Tetrud JW, Irwin I, et al. Oral levodopa/carbidopa solution versus tablet in Parkinson's disease with severe fluctuations: a pilot study. Neurology 1993:43:1036-9.

44 Ostergaard K, Sunde N, Dupont E. Effects of bilateral stimulation of the subthalamic nucleus in patients with severe Parkinson's disease and motor fluctuations. Mov Disord 2002; 17:693-700.

45 The Deep-Brain Stimulation for Parkinson's Disease Study Group. DeepBrain Stimulation of the Subthalamic Nucleus or the Pars Interna of the Globus Pallidus in Parkinson's disease. N Engl J Med 2001;345:956-63.

46 Narabayashi H, Yokochi F, Nakajima Y. Levodopa-induced dyskinesia and thalamotomy. J' Neurol Neurosurg Psychiatry 1984;47:831-9.

47 Laitinen LV. Pallidotomy for Parkinson's disease. Neurosurg Clin N Am 1995:6:105-12.

48 Fox SH, Henry B, Hill M, et al. Stimulation of cannabinoid receptors reduces levodopa-induced dyskinesia in the MPTP-lesioned nonhuman primate model of Parkinson's disease. Mov Disord 2002;17:1180-7.

49 Bove J, Marin C, Bonastre M, et al. Adenosine A2A antagonism reverses levodopa-induced motor alterations in hemiparkinsonian rats. Synapse 2002;46:251-7.

50 Oh JD, Bibbiani F, Chase TN. Quetiapine attenuates levodopa-induced motor complications in rodent and primate parkinsonian models. Exp Neurol 2002;177:557-64.

51 Dialdetti R, Melamed E. New drugs in the future treatment of Parkinson's disease. J Neurol 2002;249(suppl 2):I130-5.

52 Bronte-Stewart H. Parkinson's disease: surgical options. Curr Treat Options Neurol 2003;5:131-47.

\section{Call for papers}

10th European Forum on Quality Improvement in Health Care 13-15 April 2005, ExCel, Docklands, London For further information on how to submit your paper please go to: http://www.quality.bmipg.com 